\title{
Zoneamento geológico-geotécnico de porção da região da Costa Verde-RJ, escala 1:10.000
}

\author{
Alberto Ferreira do Amaral Junior \& Lázaro Valentin Zuquette
}

\begin{abstract}
Resumo Este trabalho apresenta um conjunto de atividades desenvolvidas e os resultados obtidos no decorrer dos estudos relacionados ao mapeamento geotécnico e a movimentos de massa gravitacionais realizados em uma área que compreende $60 \mathrm{~km}^{2}$, sendo $41 \mathrm{~km}^{2}$ de encosta e $19 \mathrm{~km}^{2}$ de planícies, localizada na região da Costa Verde, estado do Rio de Janeiro, envolvendo parte dos municípios de Itaguaí e Mangaratiba. O estudo foi realizado em três etapas distintas: definição dos atributos, levantamento de dados e análise dos resultados. Foram elaborados os mapas de substrato rochoso, materiais inconsolidados, forma da encosta, declividade, direção da inclinação do talude e uso das terras, assim como os dados de chuvas dos últimos 17 anos. Foi ainda realizado o inventário das feições de movimentos de massa gravitacionais de acordo com os critérios definidos pela UNESCO. Cerca de 140 feições foram cadastradas e classificadas como escorregamentos translacionais, quedas, rolamentos, fluxos e rastejos, sendo que $49 \%$ destes eventos não sofreram influência antrópica. A partir dos dados do inventário e dos atributos elaborou-se uma analise bivariada por correlação simples, que mostrou que a ocorrência dos movimentos são controlados por um grupo de atributos fortalece a premissa de que para estudos de movimentos de massa gravitacionais deve ser considerado um grupo significativo de atributos, e um zoneamento geológico-geotécnico em termos da predisposição da área quanto aos movimentos de massa gravitacionais baseado nos resultados da analise bivariada.
\end{abstract}

Palavras-chave: Mapeamento geotécnico, movimentos de massa gravitacionais, Costa Verde, Rio de Janeiro.

\begin{abstract}
Engineering geological zoning of portion of the Costa Verde region-RJ, Scale 1:10,000. This work presents procedures and results of studies related to the Engineering Geological Mapping and gravitational mass movement processes carried out in an area with $60 \mathrm{~km}^{2}$, being $41 \mathrm{~km}^{2}$ on hillside and $19 \mathrm{~km}^{2}$ on plains. It is located in the Costa Verde region, state of the Rio de Janeiro, in the municipalities of Itaguaí and Mangaratiba. The study was developed in three distinct stages: definition of the attributes, collecting of the data and analysis of the results. As result of the engineering geological mapping six maps were elaborated: rock substrate, unconsolidated materials, slope shape, slope gradient, direction of the slope gradient and land uses. The rainfall data of the last 17 years were obtained. The inventory of the features of gravitational mass movements was elaborated in accordance with the criteria defined by UNESCO, and was registered 140 features, consisting of 5 categories: translational landslides, falls, boulder rolling, flows and creep. About $49 \%$ of these features had not suffered human influence. A bivariate analysis was carried out considering the environmental data obtained during the engineering geological mapping and inventory of the features occurred in the area.
\end{abstract}

Keywords: Engineering Geological Map, Gravitational mass movement, Costa Verde.

INTRODUÇÃO O Homem ao longo dos últimos 250 anos vem explorando a Terra e modificando sua parte mais superficial profundamente, principalmente pela falta de qualquer tipo de planejamento adequado da exploração e ocupação do meio físico. Assim, tornase indispensável a utilização de uma ferramenta que oriente quanto às suas limitações e qualidades. $\mathrm{O}$ mapeamento geotécnico é esta ferramenta que tem como objetivo caracterizar e zonear o meio físico no sentido de indicar o melhor uso do território, proteger os recursos naturais, prever e alertar quanto aos eventos naturais e induzidos. Na maioria das vezes as investigações geotécnicas têm um caráter emergencial ou corretivo, para mitigar problemas existentes. Ao contrário do ma- peamento geotécnico que tem papel importante não só no diagnóstico, mas também na prevenção de situações de risco decorrente de eventos naturais ou induzidos, e com isso visa propiciar uma economia de recursos evitando obras corretivas.

Dentre os eventos que ocorrem na Terra e atingem o Homem e seus bens encontram-se os movimentos de massa gravitacionais (MMG) em regiões montanhosas, que são em muitos casos processos naturais de evolução do meio físico, e que podem ser acelerados por atividades antrópicas, potencializando as conseqüências sociais e/ou econômicas adversas, além daquelas naturalmente provocada por estes processos. $\mathrm{O}$ entendimento destes processos e suas relações são fundamen- 
tais para que haja um planejamento adequado de uso do solo de uma região, assim como para que medidas de controle sejam adotadas com a devida antecedência. Neste sentido foi desenvolvido em parte da região da Costa Verde, no estado do Rio de Janeiro, este estudo envolvendo a combinação dos procedimentos de mapeamento geotécnico e de inventário das feições decorrentes de eventos anteriores, com o objetivo de elaborar um zoneamento geológico-geotécnico.

ASPECTOS BIBLIOGRÁFICOS Diversas regiões no mundo, principalmente de elevadas altitudes, são atingidas por processos naturais principalmente em épocas de chuvas intensas e durante eventos sísmicos, causando mortes e destruições.

Os estudos de movimentos de massa gravitacionais podem ser desenvolvidos na forma de inventários onde a preocupação é levantar, identificar e classificar cada feição encontrada em campo. Estudos de zoneamento estão voltados para identificação de características (atributos) que predispõem tais processos e a individualização de áreas com mesmo nível de predisposição, devido à interação dos atributos entre si.

Atualmente a pesquisa sobre MMG é bastante difundida em vários países com um número muito grande de procedimentos metodológicos utilizados para o zoneamento das áreas afetadas.

Irigaray et al. (1996b) relatam sobre a enorme variedade de métodos para realizar análises de susceptibilidade de escorregamento, fazendo uma comparação para identificar o mais apropriado. Entre eles os métodos de declividade crítica (considera a relação entre distribuição da zona de ruptura em cada unidade litológica e a declividade), matriz (método quantitativo ou qualitativo), percentagem de zonas de ruptura (baseado em modelo heurístico), indexação (modelo empírico baseado em análises do terreno), valor de informação (modelo estatístico) e regressão múltipla (obtenção de equações determinísticas).

Baeza \& Corominas (2001) afirmam que os procedimentos podem ser agrupados com base em análises geomórficas, técnicas de tratamento de dados e aproximações determinísticas. As duas primeiras são mais usadas em análise de eventos perigosos regionais enquanto que a terceira é usada para estudos detalhados, onde um fator de segurança é determinado, sendo que a técnica que se destaca é a técnica de análise multivariada (tratamento de dados) que permite a avaliação quantitativa da influência simultânea de diferentes fatores, portanto, mais realista e objetiva para a avaliação de susceptibilidade a escorregamentos.

Na tabela 1 encontram-se as principais categorias e alguns exemplos de procedimentos metodológicos que representam as diferentes categorias.

MÉTODO O método utilizado neste trabalho está baseado no levantamento de um grupo de atributos a partir de um processo de mapeamento geotécnico e utilizando análises semelhantes às de Crozier (1989), Turner \& Schuster (1996) e Guzzeti et al (1999) que são baseadas em um grupo de informações relacionado ao processo, assim como a utilizada neste trabalho. Porém, em relação aos autores citados, este trabalho considerou um grupo de atributos mais específico, relacionados aos tipos de movimentos de massa gravitacionais. Foram obtidos com o desenvolvimento de um processo de mapeamento geotécnico em escala 1:10.000, de maneira que possam ser tratados por diversos recursos. O principal ponto que diferencia os procedimentos adotados neste trabalhos dos citados refere-se à avaliação das unidades de materiais inconsolidados considerando a variação vertical e a análise dos materiais em termos de sua evolução genética.

O estudo foi executado de acordo com as etapas constantes do fluxograma da figura 1 .

As atividades reunidas na figura 1 foram agrupadas em três grandes etapas, a saber:

Etapa 1: A área foi mapeada com objetivo de identificar e delimitar as zonas de ocorrência dos atributos constantes da tabela 2 , selecionados de uma listagem mais ampla de atributos proposta por Zuquette (1993); e que apresentam relação direta com a ocorrência de movimentos de massa gravitacionais, e que foram considerados na analise bivariada por correlação simples entre a ocorrência de feições e a distribuição em área considerando os atributos.

Etapa 2: Consistiu no armazenamento das informações obtidas na etapa anterior;

Etapa 3: Foram elaboradas as análises dos resultados, em termos de distribuição espacial dos atributos e bivariada por meio de correlações simples entre a freqüência dos movimentos de massa gravitacionais e os atributos predisponentes mapeados na região.

\section{CARACTERÍSTICAS GERAIS DA ÁREA}

Localização A área de estudo está inserida nos municípios de Mangaratiba e Itaguaí, litoral sul do estado do Rio de Janeiro, na porção sudoeste da folha Itaguaí, entre as coordenadas: 606000E, $7474000 \mathrm{~N} ; 624000 \mathrm{E}$, $7462000 \mathrm{~N}$, da Zona UTM 23 Sul, totalizando $60 \mathrm{~km}^{2}$ (Fig. 2).

Características gerais Aárea de estudo está inserida em um clima tropical úmido, com evapotranspiração anual moderada e segundo a classificação de Köppen é do tipo Af. A temperatura média anual é de aproximadamente $22^{\circ} \mathrm{C}$, a média mensal é de $25^{\circ} \mathrm{C}$ no mês mais quente e $19^{\circ} \mathrm{C}$ no mês mais frio, com ventos predominantes de sudoeste e sul e pluviosidade anual que pode atingir $2100 \mathrm{~mm}$.

Geomorfologicamente a região é constituída por 3 zonas: planícies colúvio-aluvionares, planícies flúvio-marinhas e escarpas.

A vegetação natural predominante é a Mata Atlântica que ocorre nas altitudes mais elevadas, com espécies arbóreas de grande porte (30 metros de altura), arbustivas e rasteiras. Há, ainda, presença da cultura de banana na média e baixa encosta, e pastagem.

Chuvas A estação meteorológica encontra-se no dis- 
Tabela 1 - Vantagens e desvantagens dos tipos de procedimentos utilizados para zoneamentos relativos aos movimentos de massa gravitacionais.

\begin{tabular}{|c|c|c|c|}
\hline Enfoque & Vantagens & Desvantagens & Exemplos \\
\hline $\begin{array}{l}\text { Multicritério } \\
\text { (em especial } \\
\text { AHP) }\end{array}$ & $\begin{array}{l}\text { - Transformação de dados } \\
\text { quantitativos em dados } \\
\text { qualitativos; } \\
\text { - Avaliação da importância } \\
\text { relativa de cada atributo. }\end{array}$ & $\begin{array}{l}\text { - Exige uma enorme quantidade de } \\
\text { informações, conseqüentemente } \\
\text { período de tempo longo de trabalhos } \\
\text { preliminares; } \\
\text { - Para análises de muitas classes e } \\
\text { atributos faz se necessário uso de } \\
\text { ferramenta computacional. }\end{array}$ & $\begin{array}{l}\text { Rodrigues (2003), } \\
\text { Rodrigues \& } \\
\text { Zuquette (2006). }\end{array}$ \\
\hline $\begin{array}{l}\text { Determi- } \\
\text { nístico }\end{array}$ & $\begin{array}{l}\text { - Análises quantitativas, } \\
\text { considerando o fator de } \\
\text { segurança. }\end{array}$ & $\begin{array}{l}\text { - Aplicável em pequenas extensões } \\
\text { (taludes), em escala local, não aplicável } \\
\text { em escalas menores devido à quantidade } \\
\text { de informações exigidas. }\end{array}$ & $\begin{array}{l}\text { Wu \& Abdel-Latif } \\
(2000) \text {. }\end{array}$ \\
\hline $\begin{array}{l}\text { Heurístico } \\
\text { (Geomórfico) }\end{array}$ & $\begin{array}{l}\text { - Ë um método de fácil análise, } \\
\text { não necessitando de ferramentas } \\
\text { computacionais muito } \\
\text { avançadas para tal; } \\
\text { - Gera boas potencialidades } \\
\text { relativas entre os atributos, } \\
\text { aproximando-se da realidade. }\end{array}$ & $\begin{array}{l}\text { - O principal inconveniente é que o } \\
\text { conhecimento disponível dos fatores que } \\
\text { influenciam os deslizamentos pode ser } \\
\text { inadequado e subjetivo dependendo da } \\
\text { experiência do pesquisador; } \\
\text { - Devido ao grau de subjetividade } \\
\text { inviabiliza a comparação com outros } \\
\text { autores. }\end{array}$ & Anbalagan (1992). \\
\hline $\begin{array}{l}\text { Estatístico } \\
\text { (bivariada e } \\
\text { multiva-riada). }\end{array}$ & $\begin{array}{l}\text { - Relacionam o aspecto } \\
\text { probabilístico; } \\
\text { - Objetividade. } \\
\text { - Trabalha com dados } \\
\text { qualitativos e quantitativos } \\
\text { - Capacidade de analisar a } \\
\text { influência de cada atributo }\end{array}$ & $\begin{array}{l}\text { - Multivariada necessita de muitos dados } \\
\text { e de boa qualidade. }\end{array}$ & $\begin{array}{l}\text { Carrara (1983), } \\
\text { Carrara et. al (1991). }\end{array}$ \\
\hline
\end{tabular}

AHP - Analytical Hierarchy Process

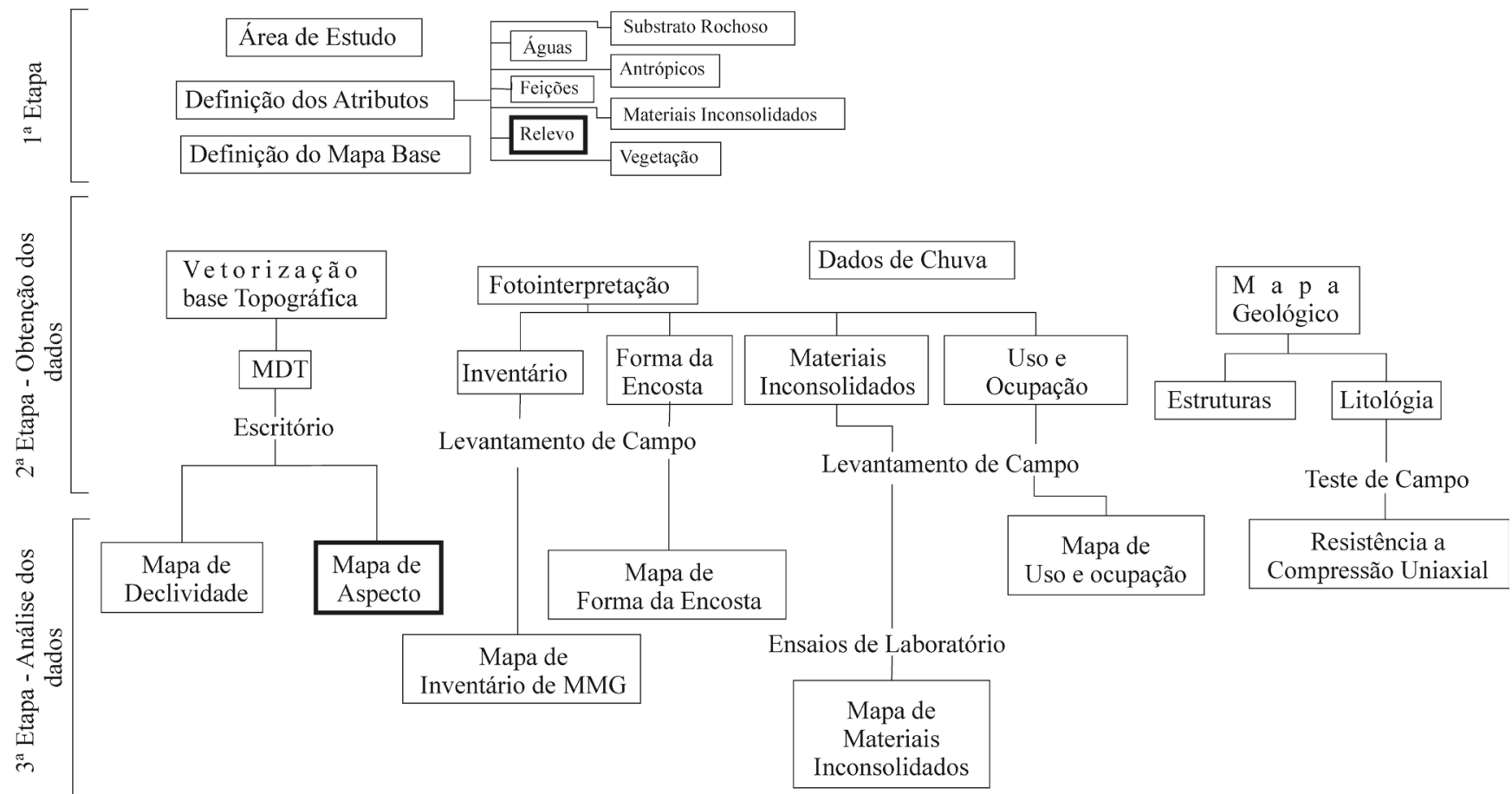

Figura 1 - Fluxograma das atividades desenvolvidas no mapeamento geotécnico da região da Costa Verde-RJ. 
Tabela 2 - Componentes e atributos levantados durante o mapeamento geotécnico (adaptado de Zuquette, 1993).

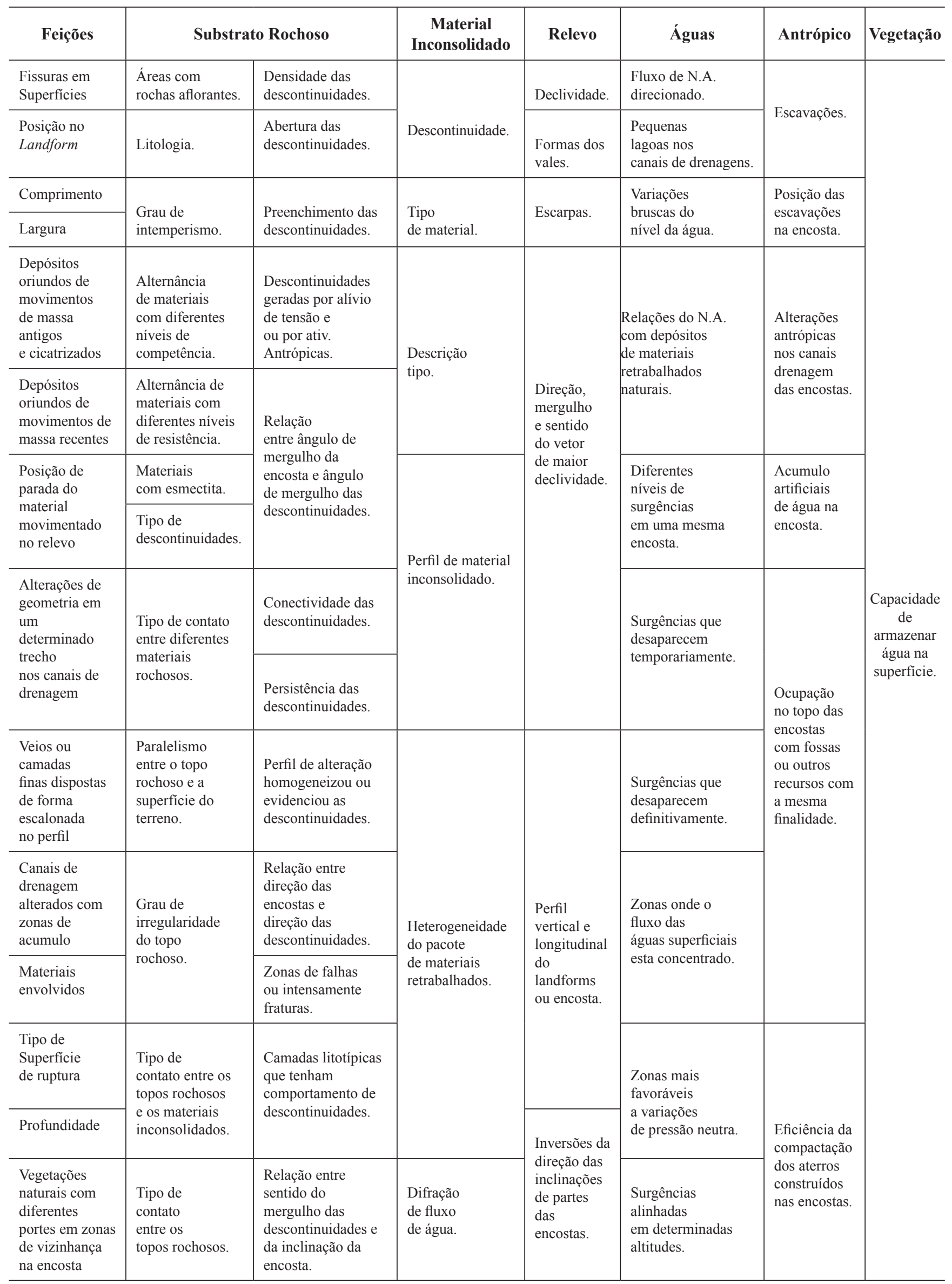


trito de Coroa Grande (Itaguaí), sobre os cuidados da ANA (Agencia Nacional de Águas) com registros diários, num período de 17 anos, desde 1989 a 2006 (Fig. 3), para os quais observou-se uma variação de chuva acumulada anual entre $1642 \mathrm{~mm}$ e $2618 \mathrm{~mm}$. Analisando os valores diários de chuva e o número de dias em que chove mensalmente, foi verificado que cerca de 5\% das chuvas diárias estão acima de $60 \mathrm{~mm}$ e que em $31 \%$ dos meses chove mais que 10 dias.

A região metropolitana do Rio de Janeiro tem implantado o sistema de "Rio Alerta" proposto por D'orsi et al. (1997). Baseado em eventos ocorridos, considerando os dados de chuva diários e acumulados de 4 dias (96 horas). Analisando os limites de ruptura propostos por D’orsi et al. (1997) e a distribuição das chuvas encontrou-se 28 eventos (no período de 1989 a 2006) de chuvas (Fig. 4) que ultrapassam o limite de ruptura.

RESULTADOS Os resultados serão apresentados separadamente em função dos componentes do meio ambiente e dos documentos cartográficos elaborados durante o desenvolvimento do trabalho.

Forma da Encostas As áreas com diferentes formas das encostas foram individualizadas levando em consi-

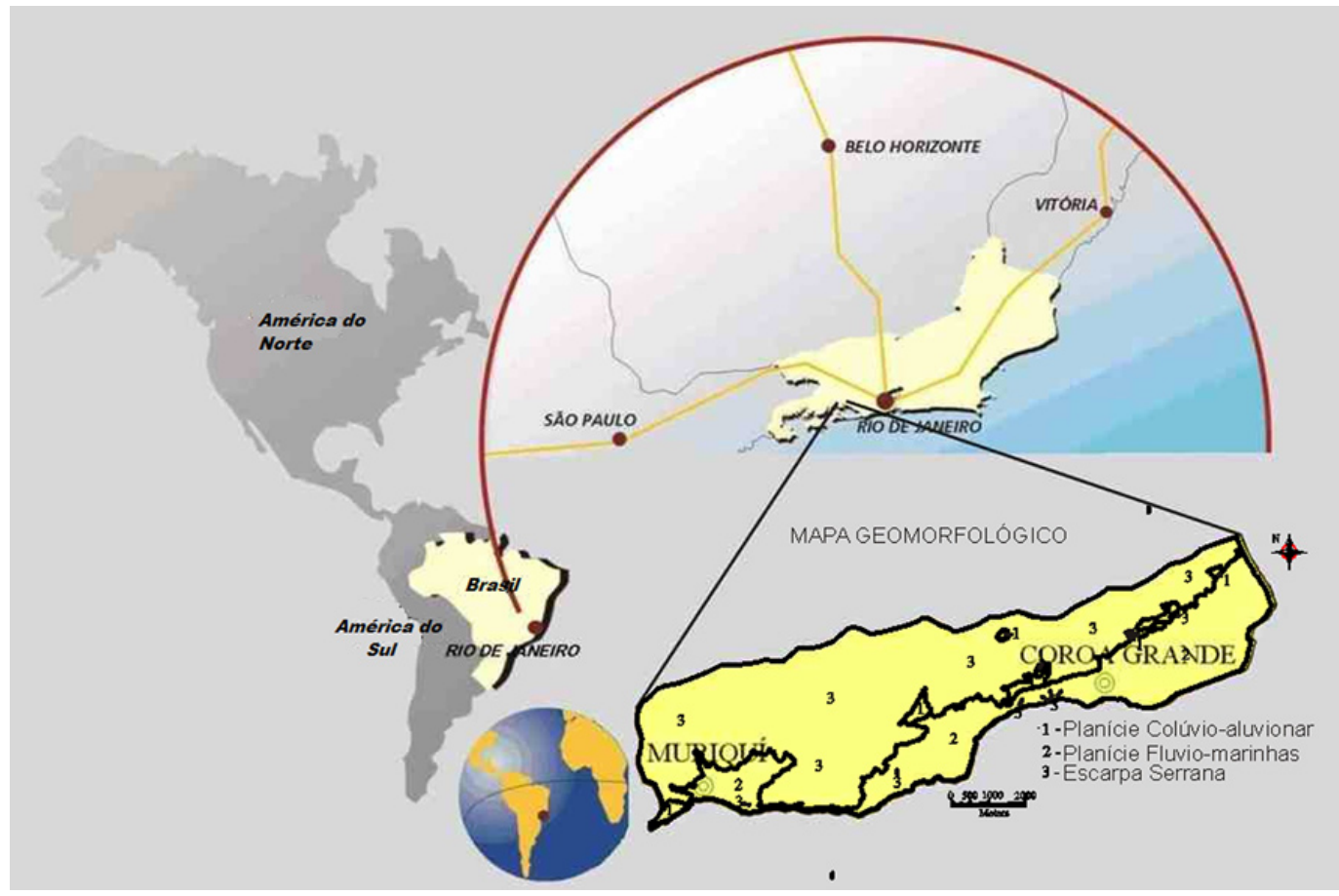

Figura 2 - Localização da área de estudo.

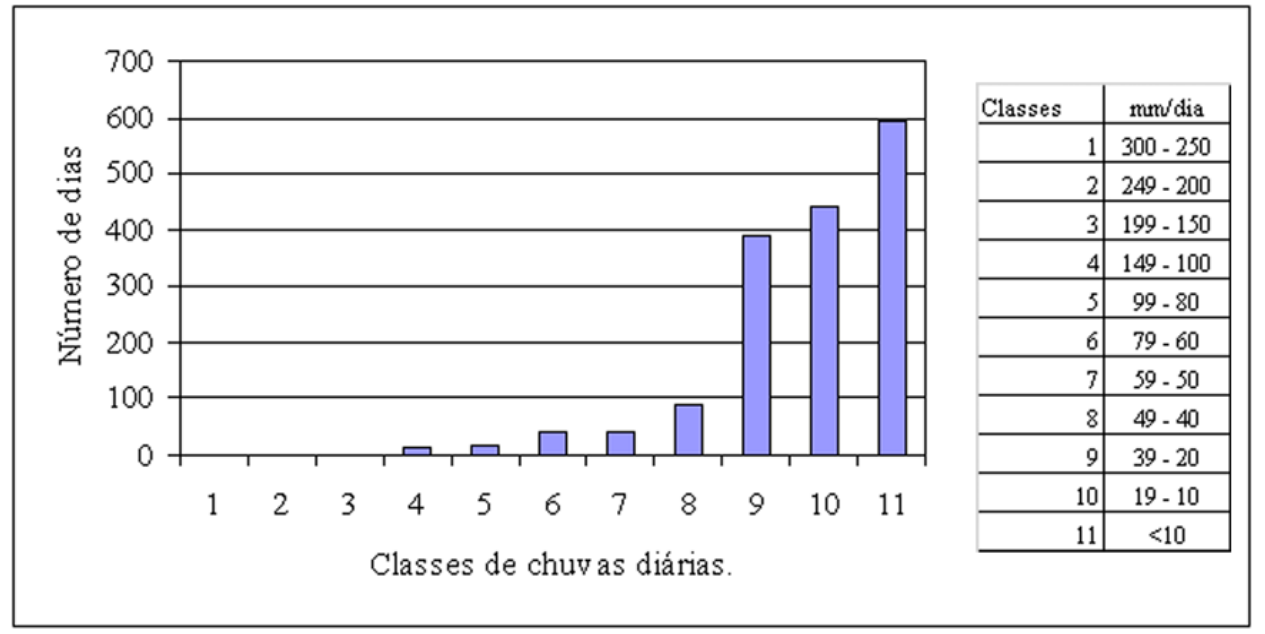

Figura 3 - Distribuição das chuvas diárias no período de 1989 até 2006 (Fonte ANA, 2006). 
deração seus perfis verticais e horizontais, segundo os padrões de Ruhe (Fig. 5).

Direção do Mergulho do Talude A partir do modelo digital de terreno foi gerada a carta contendo 9 classes (plano, norte, sul, leste, oeste, sudeste, sudoeste, nordeste, noroeste), sendo que a maioria pertence às classes sul e sudeste.

Usos do Solo A área tem 6 classes de usos bem individualizadas: área industrial com $1,5 \mathrm{~km}^{2}$, área urbana com $9,1 \mathrm{~km}^{2}$, cultivo de banana com $0,9 \mathrm{~km}^{2}$, mineração com $0,07 \mathrm{~km}^{2}$, pastagem com $8,8 \mathrm{~km}^{2}$ e Mata Atlântica com $41,3 \mathrm{~km}^{2}$.

Declividade Inicialmente elaborou-se uma carta de declividade com 9 classes com intervalo de $10^{\circ}$, variando de 0-90, e a partir da avaliação da freqüência das classes foi elaborada uma segunda carta de declividade com 6 classes variando de 0 a $>50^{\circ}$, com intervalo de $10^{\circ}$.

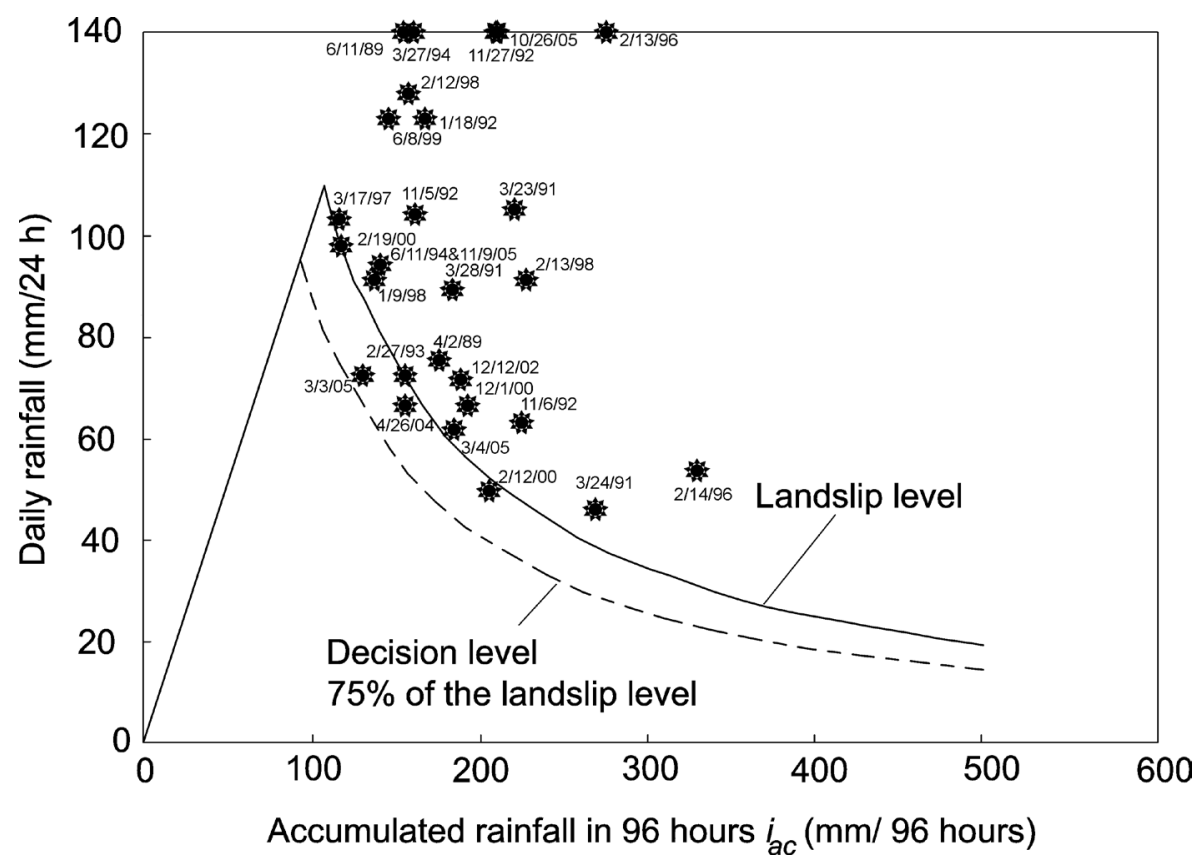

Figura 4 - Eventos diários de chuvas, no periodo 1989-2006, que ultrapassaram o limite de ruptura proposto por D'orsi et al. (1997).

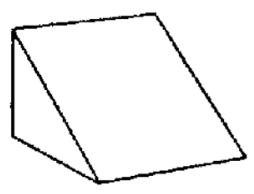

LL

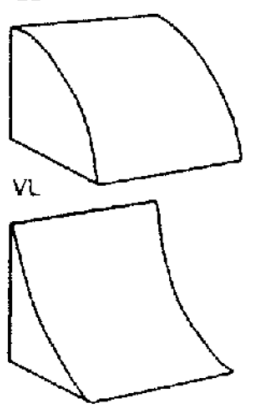

$\mathrm{CL}$

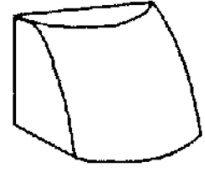

LV

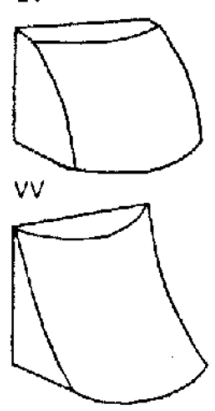

CV

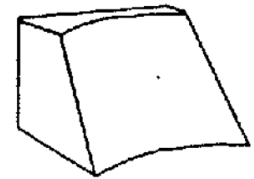

LC

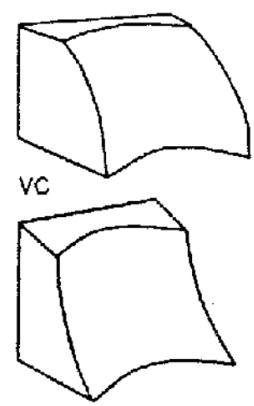

CC
LEGENDA

(primeira letra refere-se ao perfil vertical e a segunda ao horizontal)

LL RETILÍNEA RETILÍNEA

LV RETILÍNEA CONVEXA

LC RETILÍNEA CÔNCAVA

VL CONVEXA RETILÍNEA

VV CONVEXA CONVEXA

VC CONVEXA CONNCAVA

CL CÔNCAVA RETILÍNEA

CV CÔNCAVA CONVEXA

CC CÔNCAVA CÔNCAVA

Figura 5 - Formas das vertentes (S Retilíneo, V convexo, C côncavo), Ruhe apud Mitchell (1991). 
Mapa do Substrato Rochoso A área de estudo é composta por biotita gnaisse, migmatito, granito e depósitos quaternários (Fig. 6).

O granito é acinzentado, discretamente foliado, com textura variando, entre fina e média, e são porfiroclásticos em amplos domínios.

O migmatito tem neossoma granitóide de granulação fina a média, em parte pegmatóide, com veios de quartzo, e com uma faixa de transição com Biotita Gnaisse, da ordem de 20 metros de espessura.

O biotita gnaisse é melanocrático, de granulação média a grossa, com biotita (predominância) de granulação fina, quartzo de granulação média a grossa, feldspatos de granulação grossa.

Como estruturas geológicas tem-se a foliação no biotita gnaisse, em média, com atitude 335/25, e fraturas, predominantemente com 2 orientações: $\mathrm{N} 40 \mathrm{E} / 80 \mathrm{SE}$ e N43W/85SW, que associadas a juntas de alívio e foliação isolam blocos.

Foram executados alguns ensaios com o esclerômetro de Schmidt para avaliação da resistência à compressão uniaxial dos maciços rochosos e para verificar o grau de alteração dos litotipos (Tab. 3).

Mapa dos Materiais Inconsolidados Ocorrem, na área, materiais inconsolidados transportados expressivos nas encostas com tálus e colúvios, e ocorrem também os solos residuais de biotita gnaisse, migmatito e granito (Fig. 7).

\section{MATERIAIS INCONSOLIDADOS RESIDUAIS}

Biotita Gnaisse Solos residuais originados da decomposição de biotita gnaisse são muitos semelhantes aos solos residuais de migmatito, somente sendo possível a diferenciação com a ocorrência de horizontes saprolí- ticos. Algumas características geotécnicas destes solos encontram-se na tabela 4.

Residual Maduro (SRMgp) Estes materiais inconsolidados são de textura areno-silto-argilosa com pedregulhos, e grãos de quartzo angulosos. Predominantemente estes horizontes são de pequenas a grandes espessuras (desde 0,1 a 20 metros).

Residual Jovem (SRJgp) Estes materiais inconsolidados são de textura areno-siltosa com pouca argila e vestígios de pedregulho, com grãos de quartzo angulosos. Sua distribuição granulométrica é dada por: $4 \%$ de pedregulho, $68,5 \%$ de areia, $21 \%$ de silte e $6,5 \%$ de argila. Predominantemente estes horizontes são de pequenas a médias espessuras (desde 0,2 a 8 metros).

Saprolítico ( $S g p$ ) Estes materiais inconsolidados são de textura areno siltosa com pouca argila e vestígios de pedregulho. Apresentam grãos de quartzo angulosos e são ricos em mineral biotita. Sua distribuição granulométrica é dada por: $1 \%$ de pedregulho, $69 \%$ de areia, $25 \%$ de silte e $5 \%$ de argila. Predominantemente estes solos são de média a grande espessura $(\approx 3-25$ metros $)$, com preservação principalmente das foliações e outras estruturas, como as fraturas.

Migmatito Os materiais inconsolidados residuais dos migmatitos são de fácil identificação em campo devido à singularidade de horizontes de estruturas migmatíticas preservadas. Os valores dos ensaios realizados em laboratório encontram-se na tabela 5.

\section{Residual Maduro (SRMm)}

Estes materiais inconsolidados são em geral de textura

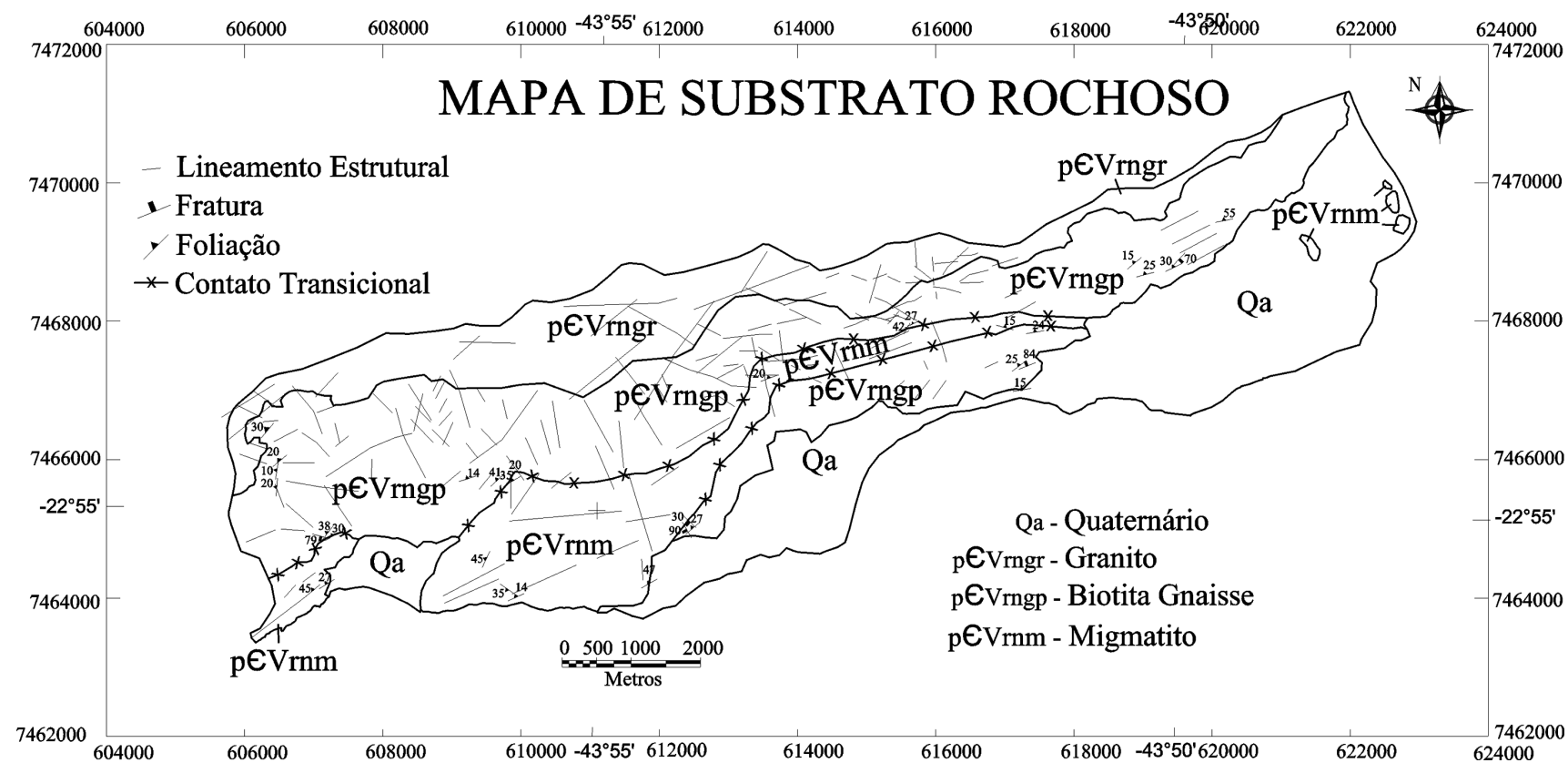

Figura 6 - Mapa de substrato Rochoso. 
Tabela 3 - Comparação entre níveis de alterações e características geotécnicas.

\begin{tabular}{c|c|c|c|c|c}
\hline \multirow{3}{*}{ Litotipo } & \multicolumn{5}{|c}{ Propriedades geotécnicas } \\
\cline { 2 - 6 } & Nível de alteração (ISRM 1983) & $\gamma_{\mathrm{d}}\left(\mathrm{kN} / \mathrm{m}^{3}\right)$ & $\gamma_{\text {sat }}\left(\mathrm{kN} / \mathrm{m}^{3}\right)$ & $\mathrm{n}(\%)$ & $\mathrm{RCU}(\mathrm{MPa})$ \\
\hline \multirow{3}{*}{ Migmatito } & I & $26,4-25,3$ & $26,5-25,7$ & $3,31-0,32$ & $77,1-58,3$ \\
\cline { 2 - 6 } & II & $24,9-24,1$ & $25,0-24,1$ & $1,54-0,90$ & $57,2-52,0$ \\
\cline { 2 - 6 } & III & $25,3-24,2$ & $25,4-24,7$ & $5,26-0,59$ & $29,8-28,2$ \\
\hline \multirow{3}{*}{ Biotita Gnaisse } & IV & $26,3-23,4$ & $26,4-23,9$ & $9,76-0,89$ & $21,0-19,0$ \\
\cline { 2 - 6 } & I & $26,6-26,5$ & $26,6-26,5$ & $0,37-0,20$ & $62,5-62,0$ \\
\cline { 2 - 6 } & II & $25,0-24,0$ & $25,3-24,4$ & $6,46-3,46$ & $35,5-32,9$ \\
\cline { 2 - 6 } & III & $24,8-21,1$ & $25,2-22,6$ & $15,15-3,40$ & $31,6-22,4$ \\
\hline
\end{tabular}

$\gamma_{\mathrm{d}-\text { Peso específico aparente seco } /} \gamma_{\text {sat }- \text { Peso específico saturado / n - Porosidade / RCU - Resistência a Compressão Uniaxial }}$

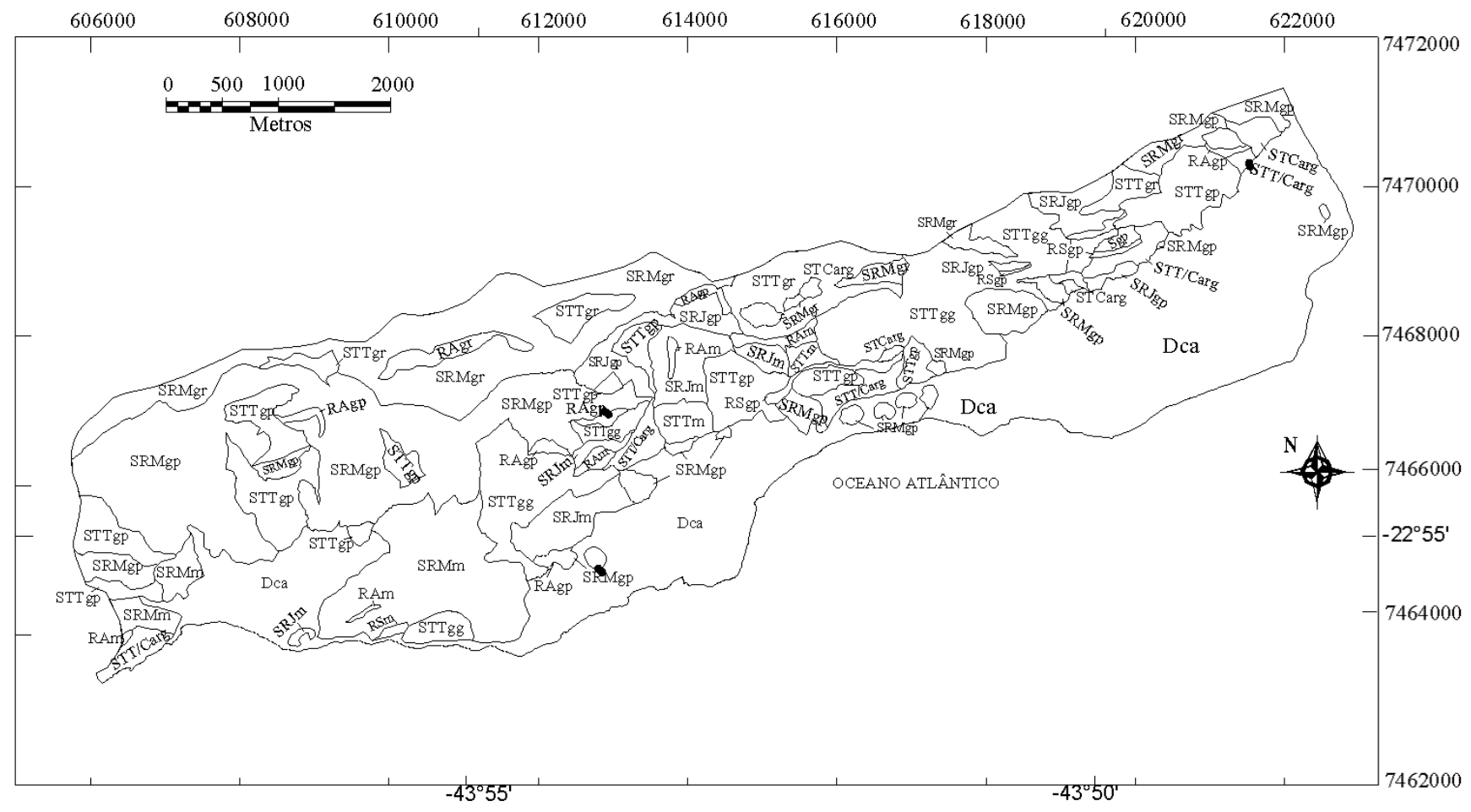

Figura 7 - Mapa de Materiais Inconsolidados.

LEGENDA

RSgp - Rocha Sã (Biotita Gnaisse)

RSm - Rocha Sã (migmatito)

Dca-Depósitos Colúvio-Aluvionares

SRMgr - Solo Residual Maduro (Granito)

RAgr - Rocha Alterada (Granito)

SRMm - Solo Residual Maduro (Migmatito)
SRJm - Solo Residual Jovem (Migmatito)

RAm - Rocha Alterada (Migmatito)

SRMgp - Solo Residual Maduro (BiotitaGnaisse)

SRJgp - Solo Residual Jovem (Biotita Gnaisse)

Sgp - Saprolito (Biotita Gnaisse)

RAgp - Rocha Alterada (BiotitaGnaisse)

STTgp - Solos Transportados Tálus com blocos angulosos de biotita gnaisse

STTgr - Solos Transportados Tálus com blocos arredondados de granito

STTgg - Solos Transportados Tálus com blocos angulosos de migmatito

STTm - Solos Transportados Tálus com blocos angulosos e arredondados

STCarg - Solo Transportado Coluvionar argiloso

STT/Carg-Solos Transportados Tálus/Colúvio argiloso 
Tabela 4 - Resultados dos ensaios para os materiais inconsolidados residuais de biotita gnaisse.

\begin{tabular}{l|c|c|c}
\hline & SRMgp & SRJgp & Sgp \\
\hline$\gamma$ campo $\left(\mathrm{kN} / \mathrm{m}^{3}\right)$ & $15,15-15,97$ & $16,45-17,51$ & $14,05-15,75$ \\
\hline$\gamma \mathrm{d} \mathrm{campo}\left(\mathrm{kN} / \mathrm{m}^{3}\right)$ & $13,09-13,55$ & $14,56-15,14$ & $11,79-13,21$ \\
\hline$\gamma \mathrm{S}\left(\mathrm{kN} / \mathrm{m}^{3}\right)$ & - & 25,80 & 25,58 \\
\hline $\mathrm{e}$ & - & $0,70-0,77$ & $0,94-1,17$ \\
\hline $\mathrm{n}$ & - & $0,42-0,43$ & $0,48-0,54$ \\
\hline $\mathrm{Wm}(\%)$ & $15,26-15,73$ & $10,50-15,65$ & $18,95-21,05$ \\
\hline$\theta(\%)$ & - & $17,55-23,69$ & $23,95-29,15$ \\
\hline Sr $(\%)$ & - & $37,80-57,34$ & $46,48-57,44$ \\
\hline$\Phi\left(^{\circ}\right)$ & 37,5 & 41 & 32 \\
\hline $\mathrm{C}(\mathrm{kPa})$ & 14,5 & 17,5 & 26,5 \\
\hline$\Phi \mathrm{r}\left({ }^{\circ}\right)$ & 32 & 42,5 & 32 \\
\hline $\mathrm{Cr}(\mathrm{kPa})$ & 8 & 4,5 & 10 \\
\hline $\mathrm{K}_{20}(\mathrm{~cm} / \mathrm{s})$ & $5,5 \mathrm{E}-04$ & $1,1 \mathrm{E}-06$ & $9,2 \mathrm{E}-04-1,4 \mathrm{E}-05$ \\
\hline Pedregulho $(\%)$ & - & 4 & 1 \\
\hline Areia $(\%)$ & - & 68,5 & 69 \\
\hline Silte $(\%)$ & - & 21 & 5 \\
\hline Argila $(\%)$ & & & 25 \\
\hline
\end{tabular}

Nota: $\gamma$ campo é o peso específico do solo, $\gamma \mathbf{d}$ campo é o peso específico seco do solo, $\gamma \mathbf{s}$ é o peso específico dos sólidos, $\mathbf{W m}$ é a umidade gravimétrica, $\boldsymbol{\theta}$ é a umidade volumétrica, $\boldsymbol{\Phi}$ é o ângulo de atrito interno do solo, $\mathbf{C}$ é a coesão do solo, $\boldsymbol{\Phi r}$ é o ângulo de atrito residual do solo e $\mathbf{C r}$ é a coesão residual do solo, e é o índice de vazios, $\mathbf{n}$ é a porosidade, $\mathbf{S r}$ saturação, $\mathbf{K}_{20}$ é a condutividade hidráulica saturada a $20^{\circ} \mathrm{C}$.

areno-siltosa com vestígios de argila e pedregulho. Sua distribuição granulométrica é dada por: $2 \%$ de pedregulho, $75,5 \%$ de areia, $18 \%$ de silte e $4,5 \%$ de argila, e presença de grãos de quartzo angulosos. Predominantemente estes são de pequenas a medianas espessuras (0,8 a 7 metros).

Residual Jovem (SRJm) Estes materiais inconsolidados são de textura areno silto-argilosa, com distribuição granulométrica dada por: $67 \%$ de areia, $21 \%$ de silte e $12 \%$ de argila, e grãos de quartzo angulosos. Predominantemente apresentaram pequenas espessuras $(0,5$ a 3 metros).

Saprolítico ( $\mathrm{Sm})$ Texturalmente caracterizados por: $0,5 \%$ de pedregulho, $84,5 \%$ de areia, $13 \%$ de silte e $2 \%$ de argila, e com grãos de quartzo angulosos e níveis cauliníticos formados pelo intemperismo dos feldspatos. Estes solos apresentam grandes variações de espessura (desde 0,8 a 30 metros), com preservação principalmente das estruturas migmatíticas possuindo variações de níveis biotíticos, geralmente na forma de lentes, menos resistentes.

Granito Os materiais inconsolidados residuais são de difícil observação em campo devido à topografia íngreme, sendo estes solos formados pela decomposição de rochas situadas nos topos das encostas.

Residual Maduro (SRMgr) Estes materiais inconsolidados são em geral de textura areno-silto-argilosa com vestígios de pedregulho, e distribuição granulométrica dada por: $4 \%$ de pedregulho, $49 \%$ de areia, $25 \%$ silte, $22 \%$ de argila. Predominantemente apresentam espessuras medianas $(\approx 3-10$ metros), condutividade hidráulica saturada variando entre $1,6 \times 10^{-6}$ a $3,7 \times 10^{-7} \mathrm{~cm} / \mathrm{s}$, massa específica seca varia de 1,37 a $1,49 \mathrm{~g} / \mathrm{cm}^{3}$ e a massa especifica dos sólidos é de $2,755 \mathrm{~g} / \mathrm{cm}^{3}$, índice de vazios variando de 0,85 a 1,04, porosidade de 46,02 a $50,95 \%$, e ângulo de atrito interno de $32^{\circ}$ e coesão de $31,5 \mathrm{kPa}$ para condição de umidade de campo.

Residual Jovem (SRJgr) Estes materiais inconsolidados são de textura areno silto argilosa com pedregulhos, grãos de quartzo angulosos, e granulometria fina. Predominantemente são de pequenas espessuras (0,3-2 metro), e apresentam alto grau de homogeneidade.

Saprolítico (Sgr) Estes materiais inconsolidados são 
Tabela 5 - Resultados dos ensaios para os materiais inconsolidados residuais de migmatito.

\begin{tabular}{l|c|c|c}
\hline & SRMm & SRJm & Sm \\
\hline$\gamma$ campo $\left(\mathrm{kN} / \mathrm{m}^{3}\right)$ & $13,45-14,13$ & $12,84-14,06$ & $12,29-13,67$ \\
\hline$\gamma \mathrm{d}$ campo $\left(\mathrm{kN} / \mathrm{m}^{3}\right)$ & $12,47-12,97$ & $10,73-11,32$ & $12,12-12,72$ \\
\hline$\gamma \mathrm{s}(\mathrm{kN} / \mathrm{m} 3)$ & 27,20 & 29,19 & $1,02-1,12$ \\
\hline $\mathrm{e}$ & $1,10-1,18$ & $1,58-1,72$ & $0,50-0,52$ \\
\hline $\mathrm{n}$ & $0,52-0,54$ & $0,61-0,63$ & $11,17-12,75$ \\
\hline $\mathrm{Wm}(\%)$ & $7,87-9,92$ & $19,66-26,12$ & $13,73-17,73$ \\
\hline$\theta(\%)$ & $9,82-12,61$ & $22,67-29,12$ & $26,34-30,71$ \\
\hline $\mathrm{Sr}(\%)$ & $18,13-23,79$ & $33,34-47,10$ & 34 \\
\hline$\Phi\left({ }^{\circ}\right)$ & 42 & 45 & 12 \\
\hline $\mathrm{C}(\mathrm{kPa})$ & 6,5 & 6,5 & 32 \\
\hline$\Phi \mathrm{r}\left({ }^{\circ}\right)$ & 39 & 42 & 9 \\
\hline $\mathrm{Cr}(\mathrm{kPa})$ & 5,5 & 1 & $2,9 \mathrm{E}-04$ \\
\hline $\mathrm{K}_{20}(\mathrm{~cm} / \mathrm{s})$ & 18 & $3,5 \mathrm{E}-04$ & 0,5 \\
\hline Pedregulho $(\%)$ & 4,5 & 0 & 84,5 \\
\hline Areia $(\%)$ & $2,3 \mathrm{E}-05-3,0 \mathrm{E}-06$ & 67 & 13 \\
\hline Silte $(\%)$ & 2 & 21 & 2 \\
\hline Argila $(\%)$ & 76 & 12 & \\
\hline
\end{tabular}

de textura areno siltosa, com presença de argila e grãos angulosos de quartzo, de diâmetro mediano a grosso, espessuras de 0,6 a 2,5 metros, e blocos de granitos (individualizados por famílias de fraturas) em matriz argilosa.

\section{MATERIAIS INCONSOLIDADOS TRANSPORTADOS}

STTgr São encontradas nas encostas na forma de talús com blocos arredondados de granito acinzentado, de textura areno-argilosa com vestígios de pedregulhos e silte. Apresentam médias espessuras com variações de 4 a 12 metros.

STTgp São tálus com blocos angulosos de biotita gnaisse e de textura areno-siltosa, com vestígios de argila e pedregulho. A distribuição granulométrica é dada por: $2 \%$ de pedregulho, $79,5 \%$ de areia, $15 \%$ de silte, $3 \%$ de argila. Com espessuras variando de 10 a 20 metros e, com grande variação de dimensões de blocos.

STTgg Caracterizados por talús com blocos angulosos de migmatito, de textura areno-argilo-siltosa com vestígios de pedregulho. A distribuição granulométrica é dada por: $1,5 \%$ de pedregulho, $61 \%$ de Areia, $17 \%$ de silte e $20,5 \%$ de argila, e apresentam espessuras com variações de 1,5 a 7 metros, e variação grande dimensão de blocos.

STTm São talús com mistura de blocos arredondados e angulosos de diferentes litologias, de textura areno argilo-siltosa com vestígios de pedregulho, com $1 \%$ de pedregulho, $49 \%$ de areia, $24 \%$ de silte e $26 \%$ de argila, espessuras variando de 3 a 10 metros e dimensões variadas de blocos.

STT/Carg São talús com cobertura coluvionares, de textura argilo-areno-siltosa, de médias espessuras variando de 3 a 13 metros. E presença de blocos de dimensões medianas $(\approx 1 \mathrm{~m}$ de comprimento, $1,5 \mathrm{~m}$ de largura, $0,7 \mathrm{~m}$ de altura).

STCarg São formados por material coluvionar, de textura argilo areno-silto-arenosa, de espessuras médias de 20 metros. Não foi registrado nenhum evento de movimento de massa nestes tipos de materiais inconsolidados.

Colúvio-Aluvionar Depósitos de planície de inundação constituídos por areias feldspáticas, bancos e lentes de argila e níveis de cascalho.

$\mathrm{Na}$ tabela 6 encontram-se características geotécnicas de alguns materiais inconsolidados transportados.

A partir dos dados de campo e dos mapas de substrato rochoso e de materiais inconsolidados foram elaborados perfis (Fig. 8) com a distribuição espacial, permitindo observar a variação vertical e lateral dos diferentes materiais geológicos. 

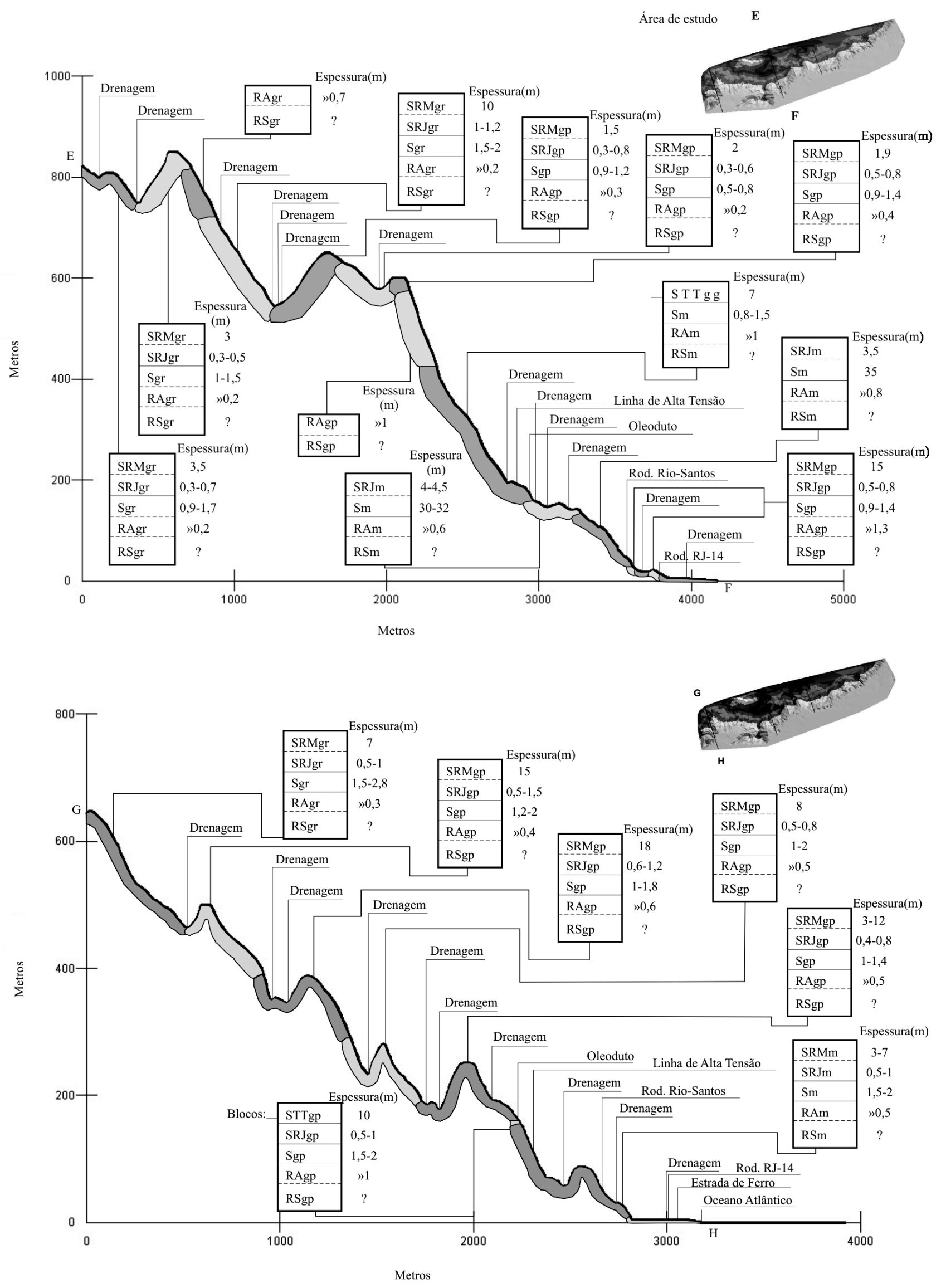

Figura 8 - Perfis verticais com a distribuição dos materiais geológicos. 
Mapa de Inventário O inventário (Fig. 9) foi desenvolvido de acordo com a proposta da WP/WLI (1990), que aborda aspectos de classificação, dimensão e loca- lização dos movimentos de massa gravitacionais, entre outros constantes da tabela 2.

Foram identificadas e caracterizadas 140 fei-

Tabela 6 - Resultados dos ensaios para os Materiais inconsolidados transportados.

\begin{tabular}{|c|c|c|c|}
\hline & STTgg & STTm & STTgp \\
\hline$\gamma$ campo $\left(\mathrm{kN} / \mathrm{m}^{3}\right)$ & $15,22-17,60$ & $16,41-17,81$ & $13,40-16,06$ \\
\hline$\gamma d$ campo $\left(\mathrm{kN} / \mathrm{m}^{3}\right)$ & $13,19-15,08$ & $12,65-13,62$ & $12,04-14,18$ \\
\hline$\gamma \mathrm{s}\left(\mathrm{kN} / \mathrm{m}^{3}\right)$ & 28,43 & 28,16 & 27,79 \\
\hline $\mathrm{e}$ & $0,88-1,15$ & $1,07-1,23$ & $0,96-1,31$ \\
\hline $\mathrm{n}$ & $0,47-0,53$ & $0,52-0,56$ & $0,49-0,57$ \\
\hline $\mathrm{Wm}(\%)$ & $15,35-15,32$ & $29,80-31,58$ & $10,79-13,28$ \\
\hline$\theta(\%)$ & $20,26-27,31$ & $39,73-48,71$ & $13,75-18,84$ \\
\hline $\operatorname{Sr}(\%)$ & $37,80-53,70$ & $68,40-81,19$ & $23,91-38,46$ \\
\hline$\Phi\left(^{\circ}\right)$ & 27 & 26 & - \\
\hline $\mathrm{C}(\mathrm{kPa})$ & 34 & 48 & - \\
\hline$\Phi r\left({ }^{\circ}\right)$ & 34 & 37 & - \\
\hline $\mathrm{Cr}(\mathrm{kPa})$ & 13 & 9 & - \\
\hline $\mathrm{K}_{20}(\mathrm{~cm} / \mathrm{s})$ & $7,4 \mathrm{E}-07$ & $5,6 \mathrm{E}-07$ & $5,4 \mathrm{E}-04$ \\
\hline Pedregulho (\%) & 1,5 & 1 & 2 \\
\hline Areia (\%) & 61 & 49 & 79,5 \\
\hline Silte $(\%)$ & 17 & 24 & 15 \\
\hline Argila (\%) & 20,5 & 26 & 3 \\
\hline
\end{tabular}

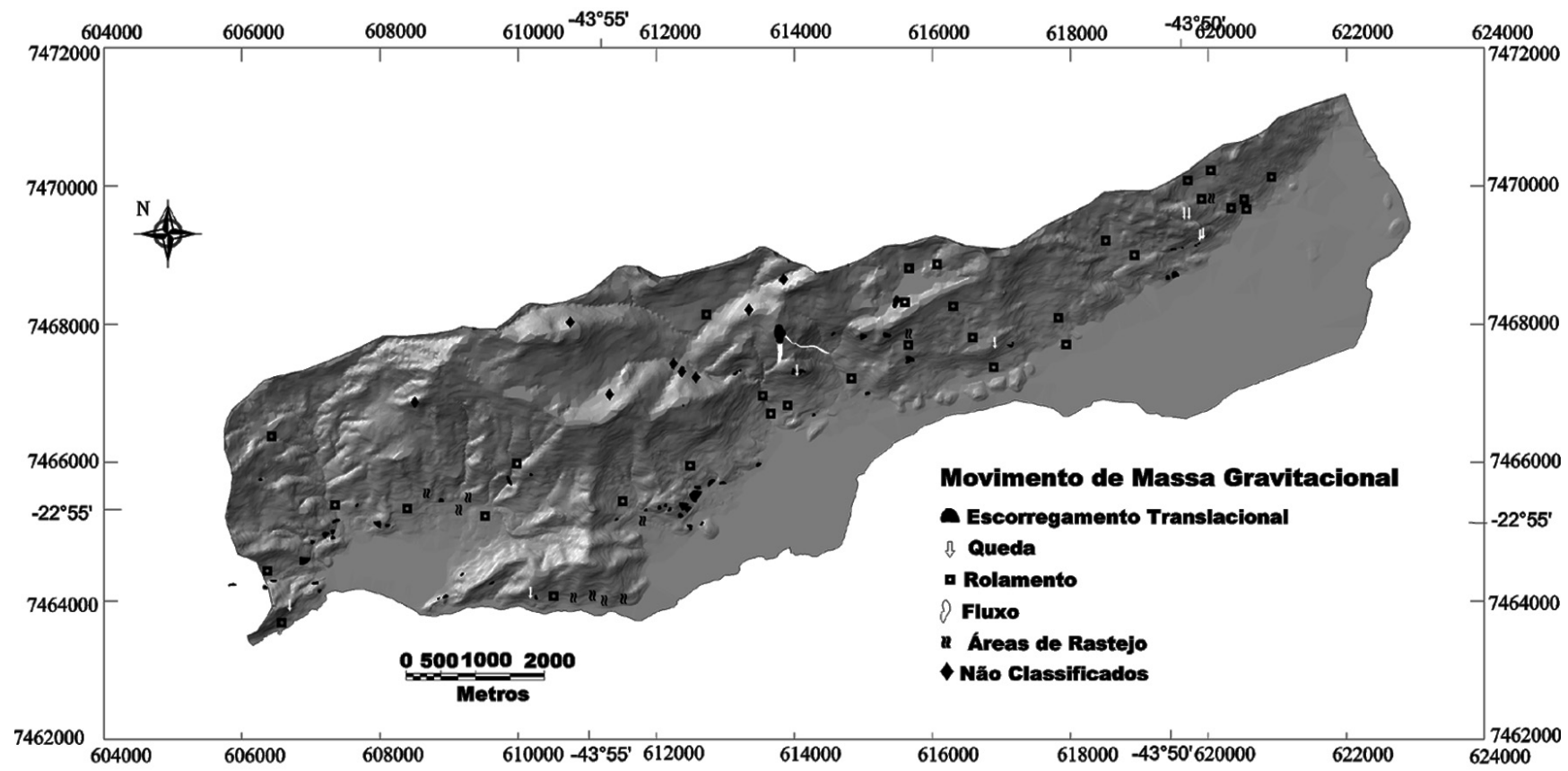

Figura 9 - Mapa de Inventário de Movimentos de Massa Gravitacionais. 
ções de movimentos de massa gravitacionais, e classificadas de acordo com Varnes (1978) e Hutchinson (1988) como: 3 fluxos, 10 rastejos, 19 escorregamentos translacionais de solo e rocha, 33 pontos de rolamento, 57 escorregamentos translacionais em solo, 7 pontos de quedas de blocos, 3 escorregamentos translacionais em rocha e 8 escorregamentos só possíveis de serem identificados em fotografia aérea devido a falta de acesso. Obteve-se relação de 3,16 eventos por $\mathrm{km}^{2}$, quando considerando somente a extensão ocupada por encosta de $41,3 \mathrm{~km}^{2}$.

Quanto à área (Fig. 10), cerca de 46,5\% dos eventos possuem menos que $50 \mathrm{~m}^{2}, 25 \%$ entre 100 $1000 \mathrm{~m}^{2}, 16 \%$ entre $50-100 \mathrm{~m}^{2}$ e $11 \%$ dos eventos com mais de $1000 \mathrm{~m}^{2}$. Enquanto em termos de volume de material mobilizado (Fig. 10) 36,8\% mobilizaram menos de $50 \mathrm{~m}^{3}, 23 \%$ acima de $1000 \mathrm{~m}^{3}$ e o restante entre 100 e $50 \mathrm{~m}^{3}$ Os rastejos, as quedas e os rolamentos foram retirados da análise de área e volume de movimentos de massa gravitacionais, porque são difíceis de serem definidos nos casos de rastejos e nos casos das quedas e rolamentos estes teriam que ser analisados em termos de blocos de rocha. Na figura 11 encontra-se a distribuição das feições em termos das deferentes alti-
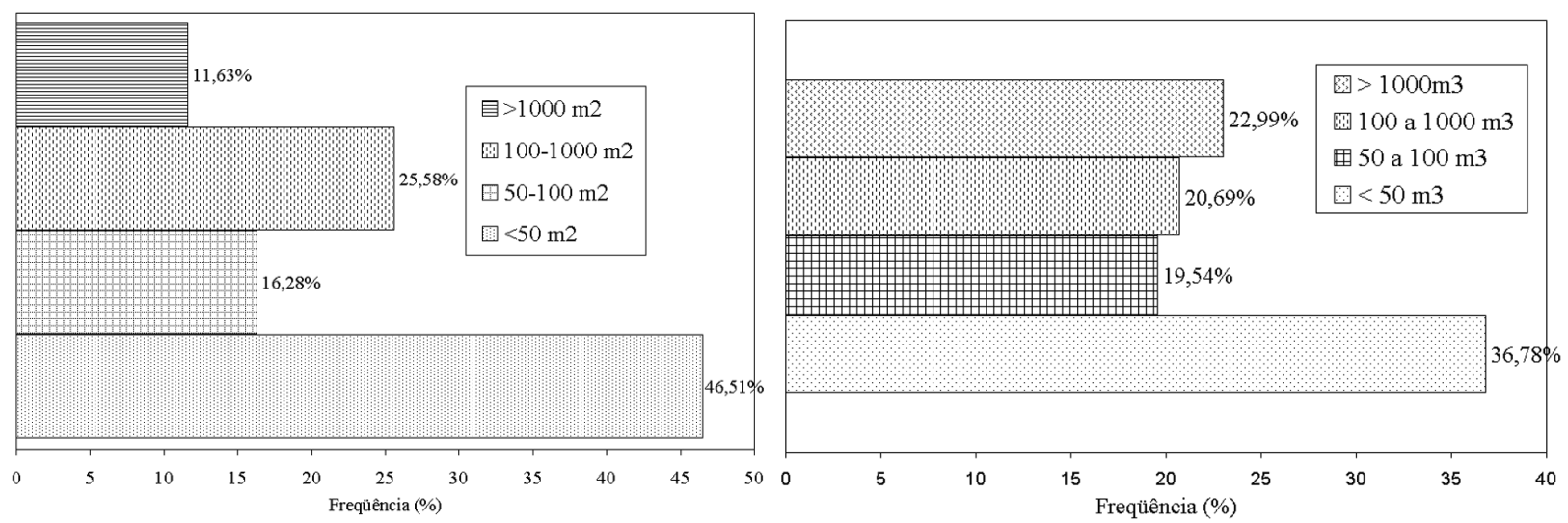

Figura 10 - Freqüência dos movimentos de massa gravitacionais quanto às áreas (A) e volumes (B).

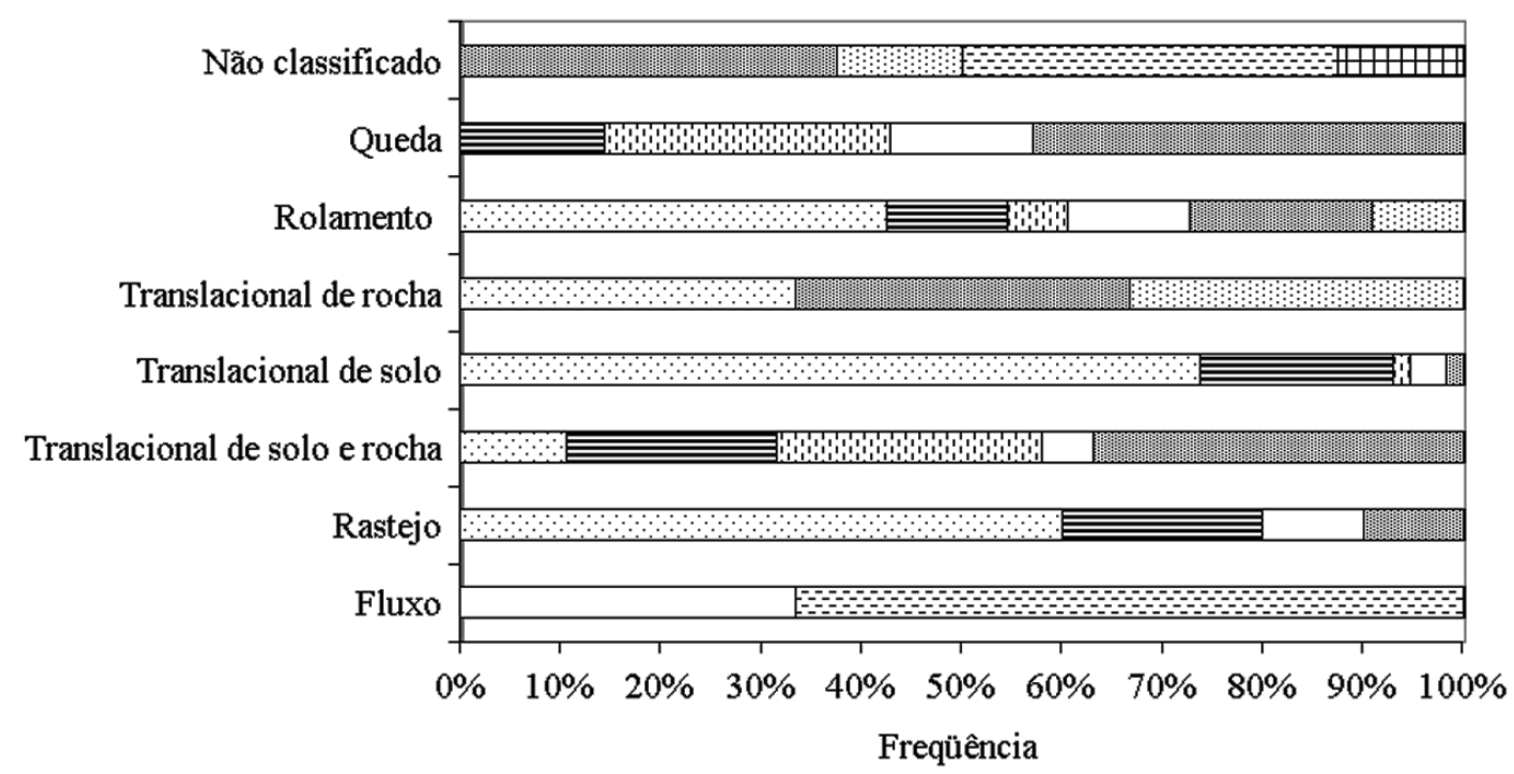

\begin{tabular}{|c|c|c|c|}
\hline $00 \mathrm{~m}$ & $50 \mathrm{~m}$ & 困 $150-200 \mathrm{~m}$ & $-300 \mathrm{~m}$ \\
\hline \30 & 图 500-700m & 㴧 700-900m & 田900- \\
\hline
\end{tabular}

Figura 11 - Freqüência das feições em relação às variações de altitudes. 
tudes. Observa-se o predomínio dos escorregamentos translacionais em rocha e solo, rolamentos e rastejos em altitudes menores que $100 \mathrm{~m}$. por outro lado, é possível observar que a ocorrência é muito pequena nas zonas com altitudes superiores a $700 \mathrm{~m}$.

ANÁLISES Considerando a chuva como deflagrador é possível verificar alguns aspectos que devem ser avaliados até com maior importância que a relação intensidade e acumulados, que é o elevado número de dias consecutivos de chuva no mês, com um período extremo de 20 dias consecutivos (3/1996), seguido de dois eventos de 18 dias consecutivos (3-4/1991, 11 12/1997). Estas chuvas mesmo de baixa intensidade infiltram-se na sua totalidade, conseqüentemente provocando uma diminuição significativa nos parâmetros de resistência, como a coesão. Como exemplo, o material inconsolidado residual de biotita gnaisse com umidade gravimétrica de $19,57 \%$ que apresentou um valor de coesão de $26,5 \mathrm{kPa}$ e ângulo de atrito interno de $32^{\circ}$, em condições de campo e, quando inundada a amostra apresentou uma umidade gravimétrica de 45,56\% houve uma queda da coesão para $13 \mathrm{kPa}$ e seu ângulo de atrito interno foi de $31^{\circ}$. Apesar da perda de coesão pequena, é o suficiente para condição de instabilização como constatado por Ahrendt (2005).

As feições estão distribuídas em relações as litologias com cerca de $47 \%$ nas áreas de ocorrência dos litotipos biotita gnaisse e migmatito, porém em termos de freqüências de eventos por área, o migmatito apresenta 7,53 eventos por $\mathrm{km}^{2}$ e o biotita gnaisse 2,62 eventos por $\mathrm{km}^{2}$. Ressalta-se que a combinação da esfoliação esferoidal com a foliação principal ou/e famílias de fraturas, no biotita gnaisse propicia condições para quedas, e posteriormente, rolamentos.

Na figura 12 encontra-se a distribuição das feições e a freqüência para as 229 unidades de forma de terreno, considerando as 9 classes.

Quanto à declividade a distribuição e freqüência dos eventos encontram-se na figura 13.

A figura 14 apresenta a distribuição e freqüência das feições para cada material inconsolidado.

Na figura 15 encontra-se a distribuição das feições por classes de direção de mergulho das encostas e a freqüência de feições por $\mathrm{km}^{2}$ das classes.

A grande maioria dos movimentos de massa gravitacionais ocorre em áreas de Mata Atlântica (71\%), $22 \%$ em pastagens e $7 \%$ em áreas urbanas, destacandose nas pastagens os escorregamentos translacionais em solo com 43,9\% .Quanto as atividades antrópicas, cerca $49 \%$ não sofreram influência antrópica, O maior destaque é a Rodovia Rio-Santos com $27 \%$.

Os fluxos estão associados aos escorregamentos translacionais de rocha e solo em elevadas altitudes, em partes com diversos canais de drenagem que se unem em um principal, tendo assim grande volume de água que facilita o transporte dos materiais geológicos deslocados pelos escorregamentos.

Os rastejos estão associados aos depósitos de tálus associados a zonas de acúmulos de água, e declividades entre $20-30^{\circ}$.

As quedas estão associadas porções onde ocorre afloramento rochoso, e nestes, individualizações de blocos de diferentes dimensões, por fraturas, foliação e juntas de alívio, que deslocam-se até zonas de menores declividades em altitudes inferiores, e de onde ocorrem

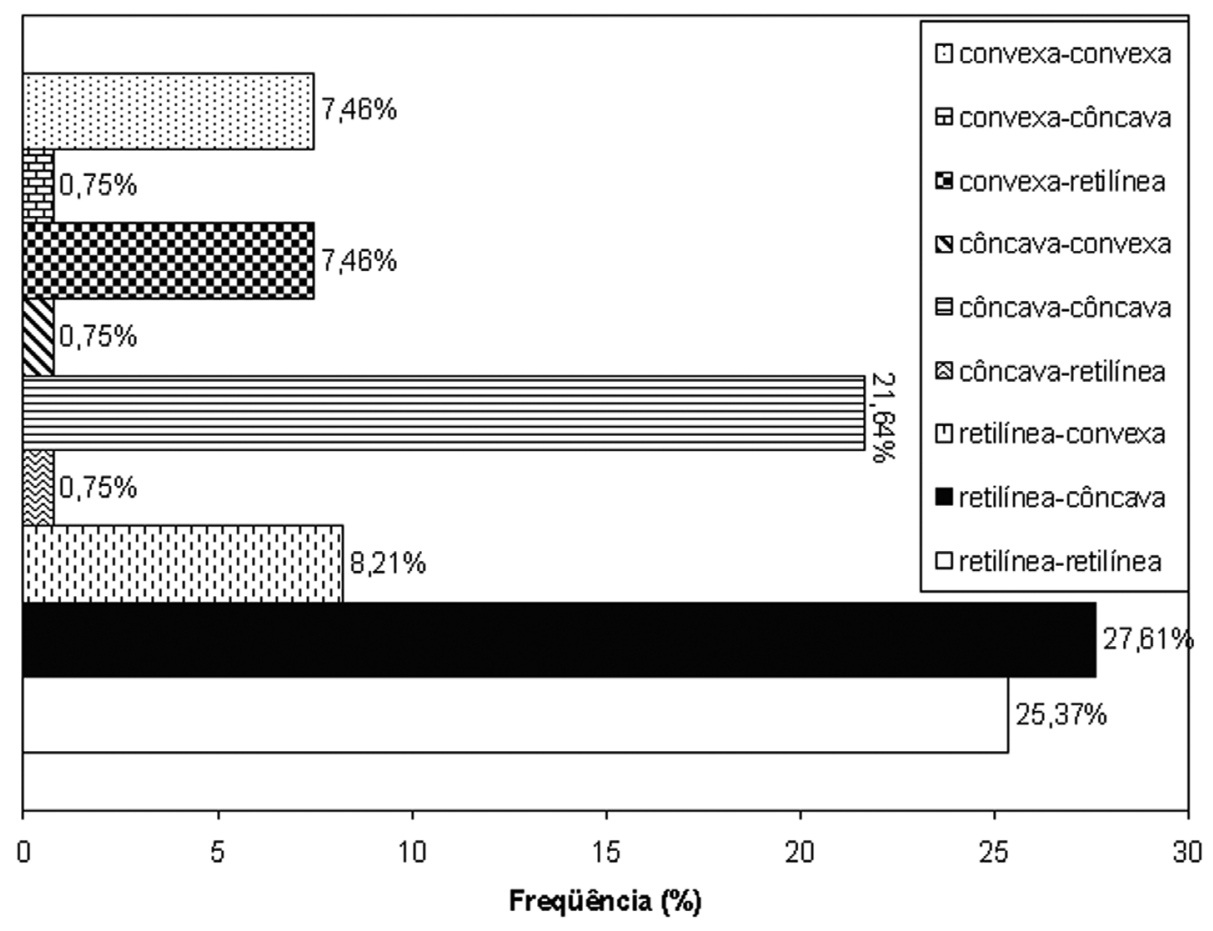

Figura 12 A - Distribuição das feições por classe de forma de encosta. 


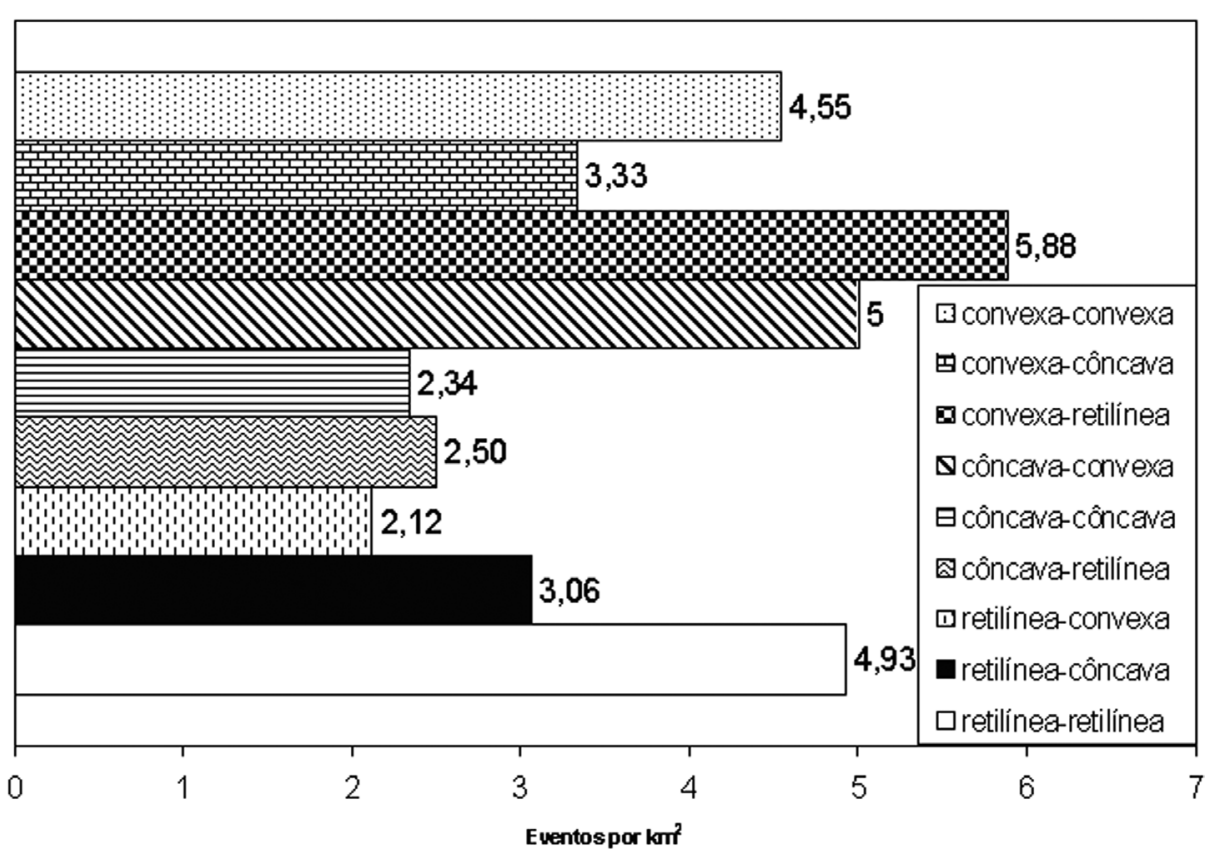

Figura 12B - freqüencia de eventos por $\mathrm{km}^{2}$ para as classes de forma de encosta.
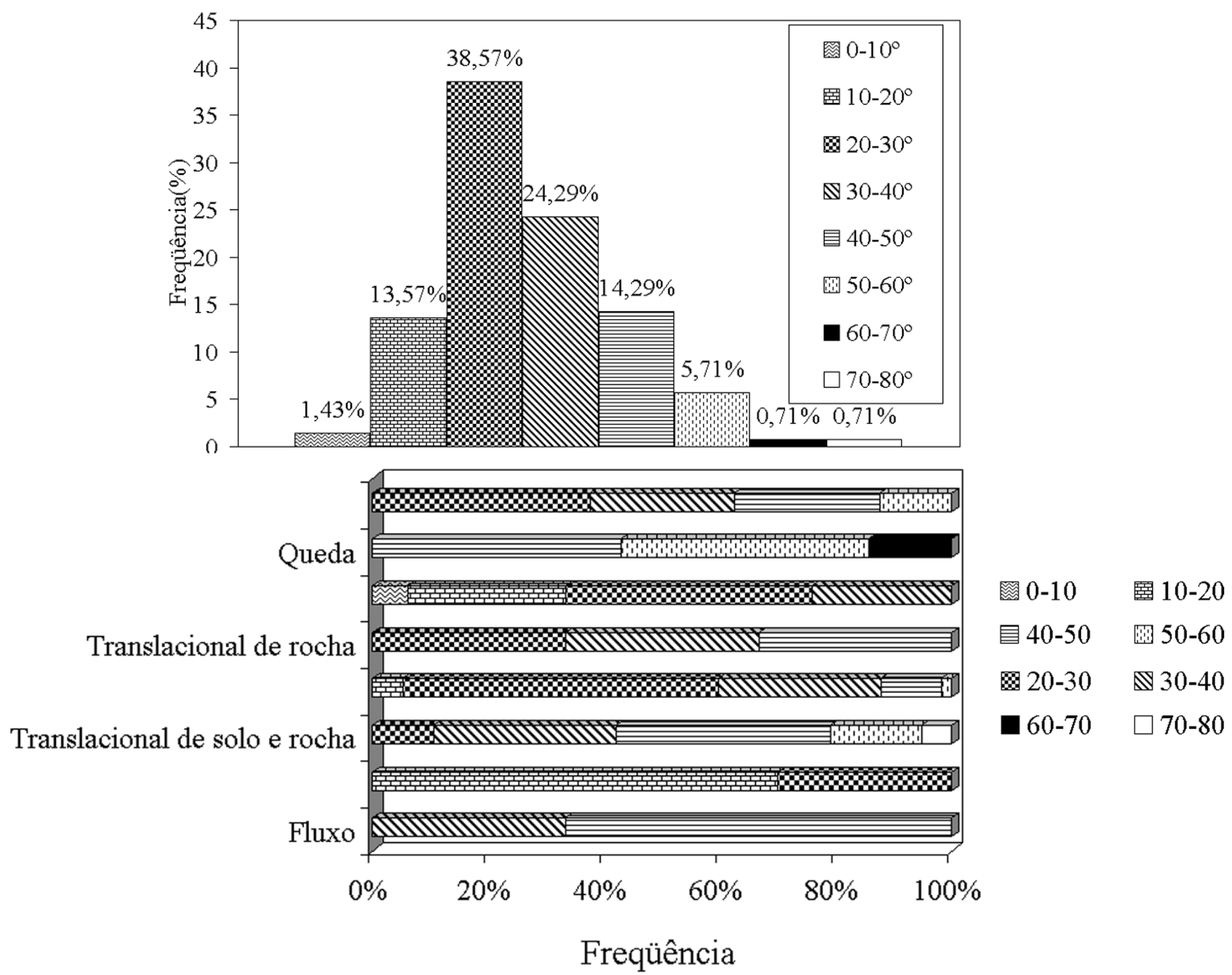

Figura 13 - Distribuição das feições por classe de declividade (A) e freqüência dos tipos de feições por classe de declividade (B). 

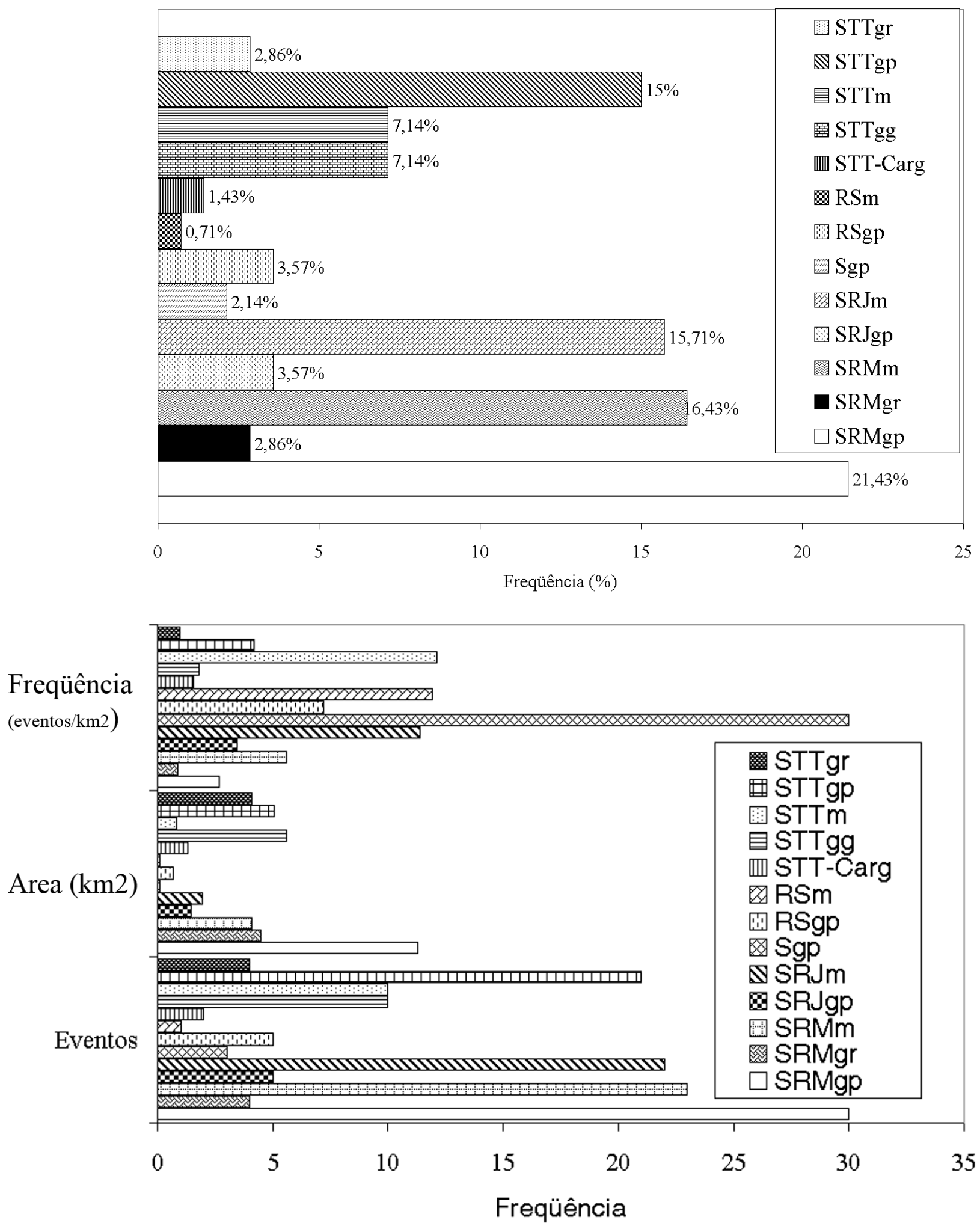

Figura 14 - Distribuição das feições por tipo de material inconsolidado (A) e freqüência de feições por $\mathrm{km}^{2}$ para os tipos de materiais inconsolidados (B).

os rolamentos em seguida ou após longos períodos.

Os escorregamentos translacionais envolvendo solos e rochas ocorrem principalmente em condições onde estruturas das rochas estão preservadas na porção alterada e recobertas por pacotes de pequena espessura de materiais inconsolidados.

Os escorregamentos translacionais em solo ocorrem principalmente envolvendo o material inconsolidado residual maduro tendo como superfície de deslocamento a descontinuidade entre o mesmo e 

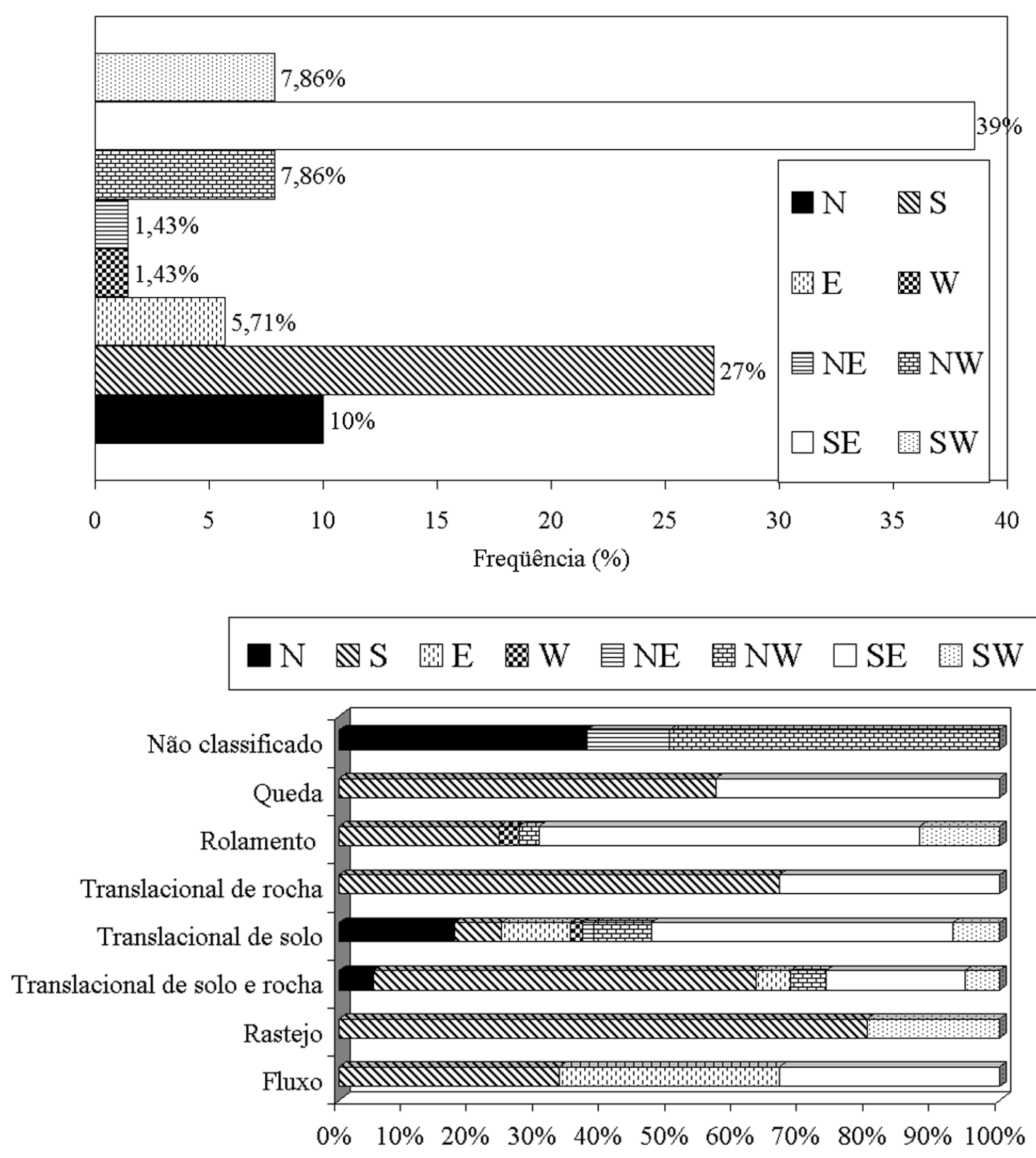

Freqüência

Figura 15 - Distribuição das feições por classe de direção de mergulho da encosta (A) e freqüência de tipos de feições para cada classe direção de face da encosta (B).

o nível saprolítico. Normalmente, tem inicio com uma superfície de ruptura circular, devido à homogeneidade do material inconsolidado residual maduro, e progride para uma superfície planar quando encontra a camada mais resistente, ou seja, o topo do saprólito.

CONCLUSÃO Os procedimentos de mapeamento geotécnico e fotointerpretação utilizados mostraram-se eficientes na obtenção dos atributos e no registro das feições.

As feições registradas na área estão associadas em sua grande maioria a encostas do tipo côncavacôn- cava, retilínea-côncava e retilínea-retilínea; e aos materiais inconsolidados Residual Maduro (SRMgp) do biotita gnaisse, Residual Maduro (SRMm) do migmatito, Residual Jovem (SRJm) do migmatito, e os transportados (STTgp - tálus) e o (STTgg - tálus) e (STTm tálus). Cerca de $62 \%$ das feições apresentam extensões menores que $100 \mathrm{~m}^{2}$, e quanto ao volume de material geológico mobilizado $23 \%$ têm valores maiores que $1000 \mathrm{~m}^{3}$. A maioria das feições ocorre entre $20^{\circ}$ e $50^{\circ}$ de declividade, em encostas voltadas para sul e sudeste. 


\section{Referências}

Ahrendt A. 2005. Movimentos de massa gravitacionais - proposta de um sistema de previsão: aplicação na área urbana de Campos dos Jordão - SP. São Carlos, Tese de Doutoramento, Escola de Engenharia de São Carlos/USP, $360 \mathrm{p}$.

Ambalagan R.1992. Landslide hazard evaluation and zonation mapping in mountainous terrain. Engineering Geology, 32:269-277.

ANA 2006. Dados pluviométricos. Disponível em: http://hidroweb.ana.gov.br. Acessado em outubro de 2006.

Baeza C. \& Corominas J. 2001. Assessment of shallow landslide susceptibility by means of multivariate statistical techniques. Earth Surface Process and Landforms, 26: 1251-1263.

Carrara A. 1983. Multivariate models of landslide hazard identification. Mathematical Geology, 15(3):403-426.

Carrara A., Cardinali M., Detti R, Guzzetti F., Pasqui V., Reichenbach P. 1991. GIS techniques and statistical models in evaluating landslide hazard. Earth Surfaces Processes and Landforms, 16:427-445.

Crozier M.J. 1989. Landslides: Causes, Consequences and Environment. London, Routledge, 252 p.

D’orsi R., D’ávila C., Ortigão J.A.R., Dias A., Moraes L., Santos M. D. 1997. Rio-Watch: The Rio de Janeiro Landslide Watch system. In: Panamerican Symposium of Landslides \& COBRAE, 2, Rio de Janeiro, anais, v. 1, p. 21-31.

Guzzetti F., Carrara A., Cardinali M., Reichenbach P. 1999. Landslide hazard evaluation: a review of current techniques and their application in a multi-scale study, Central Italy. Geomorphology, 31:181-216.

Hutchinson J.N. 1988. General Report: Morphological and Geotechnical Parameters of Landslides in Relation to Geology and Hydrogeology. In: International Symposium on Landslides, 5th, Lausanne, abstract, v.1, p. 3-35.

Irigaray, C., Chacón, J. \& Fernández, T. 1996. Comparative analysis of methods for landslide susceptibility mapping. In: Chacón, Irigaray \& Fernández (eds.). Landslides. Balkema, Rotterdam, p. 163-171.

Irigaray C., Chacón J., Fernández T. 1996. Comparative analysis of methods for landslide susceptibility mapping. In: Chacón, Irigaray \& Fernández (eds.) Landslides. Rotter- dam, Balkema, p.163-171.

ISRM 1983. Suggested Method for Rock Characterization Testing and Monitoring. Published for International Society for Rock Mechanics, Pergamon Press, 211p.

Rodrigues B.B. 2003. Proposta de sistemática para tomada de decisão relativa a movimentos de massa gravitacionais: aplicação em Ouro Preto (MG). Rio Claro, Tese de Doutoramento, UNESP/Rio Claro, 550p.

Rodrigues B.B. \& Zuquette L.V. 2006. Construção de cartas predisponentes a escorregamento em ares urbanas usando rotina de apoio a decisão". In: Congressos Nacionais de Geotecnia, 10, Lisboa, atas, v. 3, p.669-680.

Ruhe R.V. 1975. Geomorphology: geomorphic processes and superficial geology. Boston, Honghton Mifflin, 246p.

Turner A.K. \& Schuster R.L. 1996. Landslides Investigation and Mitigation. In: __ (eds.) Special Report 247. Transportation Research Board, p. 36-75.

Turner A.K. \& Schuster R.L. 1996. Landslides Investigation and Mitigation. In: (eds.) Landslides Investigation and Mitigation. Transportation Research Board, Special Report 247, p. 36-75.

Varnes D.J. 1978. Slope Movement: Types and processes. In: Schuster R.L. \& Krizek R.J.(eds.) Landslides: Analysis and Control. Transportation Research Board Special Report 176. Washington DC, National Academy of Sciences, p.11-33.

WP/WLI - UNESCO Working Party on World Landslide Inventory 1990. A suggested method for reporting a landslide. Bulletin International Association for Engineering Geology, 41:5-12.

Wu T.H., \& Abdel-Latif M.A. 2000. Prediction and mapping of landslide hazard. Canadian Geotechnical Journal, 37(4):781-795.

Zuquette L.V. 1993. Importância do mapeamento geotécnico no uso e ocupação do meio físico: Fundamentos e guia para elaboração. São Carlos, Tese de Livre Docência, USP/EESC, 330p, 2v.

Manuscrito AE 081/2006 Submetido em 16 de março de 2007 Aceito em 01 de dezembro de 2007 